\title{
Differential responses of osteoblasts and macrophages upon Staphylococcus aureus infection
}

Therwa Hamza ${ }^{1,2}$ and Bingyun Li, $i^{1,2,3^{*}}$

\begin{abstract}
Background: Staphylococcus aureus (S. aureus) is one of the primary causes of bone infections which are often chronic and difficult to eradicate. Bacteria like S. aureus may survive upon internalization in cells and may be responsible for chronic and recurrent infections. In this study, we compared the responses of a phagocytic cell (i.e. macrophage) to a non-phagocytic cell (i.e. osteoblast) upon S. aureus internalization.
\end{abstract}

Results: We found that upon internalization, $S$. aureus could survive for up to 5 and 7 days within macrophages and osteoblasts, respectively. Significantly more $S$. aureus was internalized in macrophages compared to osteoblasts and a significantly higher (100 fold) level of live intracellular S. aureus was detected in macrophages compared to osteoblasts. However, the percentage of $S$. aureus survival after infection was significantly lower in macrophages compared to osteoblasts at post-infection days 1-6. Interestingly, macrophages had relatively lower viability in shorter infection time periods (i.e. 0.5-4 h; significant at $2 \mathrm{~h}$ ) but higher viability in longer infection time periods (i.e. 6-8 h; significant at 8 h) compared to osteoblasts. In addition, S. aureus infection led to significant changes in reactive oxygen species production in both macrophages and osteoblasts. Moreover, infected osteoblasts had significantly lower alkaline phosphatase activity at post-infection day 7 and infected macrophages had higher phagocytosis activity compared to non-infected cells.

Conclusions: S. aureus was found to internalize and survive within osteoblasts and macrophages and led to differential responses between osteoblasts and macrophages. These findings may assist in evaluation of the pathogenesis of chronic and recurrent infections which may be related to the intracellular persistence of bacteria within host cells.

Keywords: Infection, Internalization, Intracellular bacteria, S. aureus, Chronic infection, Recurrent infection

\section{Background}

Staphylococcus aureus (S. aureus) is one of the primary causes of bone infections [1-3]. These infections are often chronic, difficult to eradicate, and have high morbidity rates [4]. S. aureus can infiltrate deep into bone and soft tissue as a result of severe trauma or surgical implants [5]. Although S. aureus has traditionally been considered an extracellular pathogen, it has been reported by several groups that this bacterium can invade and survive within

\footnotetext{
*Correspondence: bili@hsc.wvu.edu

'Department of Orthopaedics, School of Medicine, West Virginia University, Morgantown, WV 26506, USA

${ }^{2}$ Department of Basic Pharmaceutical Sciences, School of Pharmacy, West Virginia University, Morgantown, WV 26506, USA

Full list of author information is available at the end of the article
}

a variety of cells such as neutrophils, macrophages, T-lymphocytes, epithelial cells, endothelial cells, fibroblasts, and osteoblasts [6-16]. One hypothesis, not yet proven, about chronic and recurrent infections is that bacteria internalize into host cells and the internalization may lead to the bacteria's evasion of the host's immune responses and provide protection from most conventional antibiotics $[17,18]$.

The primary role of osteoblasts is to synthesize bone components and induce bone matrix mineralization [19]. Osteoblasts are not traditionally considered part of the immune system. However, osteoblasts were recently found to be able to induce inflammatory cytokines and chemokines upon S. aureus internalization [20,21]. This finding may suggest an important role for osteoblasts in 
triggering immune responses after $S$. aureus infection. $S$. aureus can be internalized into osteoblasts and its internalization is believed to be mediated by binding of fibronectinbinding proteins on $S$. aureus surfaces and fibronectins on osteoblast surfaces, which are connected to the integrin dimer $\alpha_{5} \beta_{1}$ molecule [6]. Protein-ligand interaction leads to $S$. aureus adhesion and invasion by a "zipper-like" mechanism [15]. Eventually, internalized bacteria escape into the cytoplasm and may lead to host cell death by apoptosis [22]. In addition, live osteoblasts are necessary for $S$. aureus internalization as $S$. aureus could not internalize into formalin-fixed osteoblasts [10,23].

The major role of phagocytes like macrophages, neutrophils, and dendritic cells is to engulf and eliminate a wide variety of invading pathogens. As a result, high influxes of such phagocytes are expected at the infection site upon pathogen invasion. For instance, a high influx of neutrophils was detected at the infection site of $S$. aureus bone infection [24]. Unfortunately, some pathogens can survive within these phagocytes after being phagocytized which may lead to chronic diseases $[25,26]$. It was reported that $S$. aureus can survive within neutrophils and its survival may have contributed to infection persistence as well as dissemination in vivo [7]. Neutrophils are short-lived and are unlikely to carry intracellular pathogens for long [27]. Macrophages, however, are long-lived and may possibly allow surviving pathogens to invade the circulatory system from localized infection sites [28] and thereby may be more likely to contribute to chronic and recurrent infections.

The aims of this study were to compare $S$. aureus internalization in a phagocytic cell (i.e. macrophage) to a nonphagocytic cell (i.e. osteoblast) and to investigate macrophage and osteoblast responses upon S. aureus infection. We hypothesized that $S$. aureus can internalize into macrophages and osteoblasts and lead to differential responses.

\section{Results \\ Characterization of S. aureus infection of osteoblasts and macrophages}

$S$. aureus was incubated with osteoblasts or macrophages for $2 \mathrm{~h}$, with a multiplicity of infection (MOI) from 100:1 to 1000:1; the MOI represents the $S$. aureus to osteoblast or macrophage ratio. Osteoblasts and macrophages were both found to be infected. However, significantly higher ( 100 fold) numbers of intracellular $S$. aureus were found within macrophages compared to osteoblasts (Figure 1A); the intracellular colony forming units (CFUs) for infected macrophages and osteoblasts were approximately $3.5 \times$ $10^{6}$ and $3.1 \times 10^{4} \mathrm{CFU} /\left(10^{5}\right.$ cells $)$, respectively. No significant differences were observed in the same cell type at the various MOIs studied (i.e. 100:1, 500:1, and 1000:1). By contrast, significantly lower viability was observed in macrophages compared to osteoblasts at $2 \mathrm{~h}$ infection; the viability of macrophages and osteoblasts were $62-78 \%$ and $90-95 \%$, respectively (Figure 1B). No significant differences in viability for the same cell type at the MOIs investigated (i.e. 100:1, 500:1, and 1000:1) were noted following the $2 \mathrm{~h}$ infection.

At an MOI of 500:1, the number of intracellular S. aureus for both macrophages and osteoblasts increased with increasing infection time and reached a plateau at $2 \mathrm{~h}$, at which point the intracellular CFUs for macrophages and osteoblasts were $5.0 \times 10^{6}$ and $3.9 \times 10^{4} \mathrm{CFU} /\left(10^{5}\right.$ cells $)$, respectively (Figure $1 \mathrm{C}$ ). At infection times of $2-8 \mathrm{~h}$, the intracellular CFUs for macrophages were significantly higher (about 100 fold) than those of osteoblasts. At an MOI of 500:1, the viability of macrophages and osteoblasts decreased approximately linearly with increasing infection time. The viability of macrophages at infection times of 2 , 4,6 , and $8 \mathrm{~h}$ was significantly lower than that of both macrophage control and at infection time of $0.5 \mathrm{~h}$. The viability of osteoblasts at infection times of 4,6 , and $8 \mathrm{~h}$ was significantly lower than that of both osteoblast control and at infection time of $0.5 \mathrm{~h}$ (Figure 1D). In addition, the viability of macrophages was significantly lower at $2 \mathrm{~h}$ infection but significantly higher at $8 \mathrm{~h}$ infection compared to osteoblasts at corresponding infection time periods (Figure 1D).

The S. aureus infection of osteoblasts was also found to be significantly inhibited by the addition of cytochalasin D. The intracellular CFUs of S. aureus decreased significantly with increasing cytochalasin $\mathrm{D}$ at the dose range studied $(0.5-20 \mu \mathrm{g} / \mathrm{mL})$, reaching $50 \%$ inhibition at $20 \mu \mathrm{g} / \mathrm{mL}$ (Figure 1E). Relatively higher cytochalasin D doses of 10 and $20 \mu \mathrm{g} / \mathrm{mL}$ also led to significantly lower intracellular CFUs of $S$. aureus compared to the doses of $0.5,1$, and $5 \mu \mathrm{g} / \mathrm{mL}$ (Figure 1E).

S. aureus was found to be able to survive within macrophages and osteoblasts for approximately a week; live intracellular $S$. aureus was found in macrophages and osteoblasts for 5 and 7 days, respectively (Figure 2). The percentage of live intracellular $S$. aureus for both macrophages and osteoblasts decreased continuously with increasing culturing time after infection, and significantly reduced survival of $S$. aureus was found in macrophages compared to osteoblasts at the same post-infection time period (Figure 2). In addition, no differences in osteoblast proliferation were observed between infected and non-infected osteoblasts within one week post-infection (data not shown).

Confocal microscopy and transmission electron microscopy (TEM) images confirmed that S. aureus was internalized and could survive within macrophages and osteoblasts (Figure 3). Meanwhile, substantially more (likely 100 fold) $S$. aureus was internalized (not necessarily alive) by macrophages compared to osteoblasts (Figures 3A and B). Confocal microscopy imaging also found that all live $S$. aureus was inside the osteoblasts and there was no live $S$. aureus 


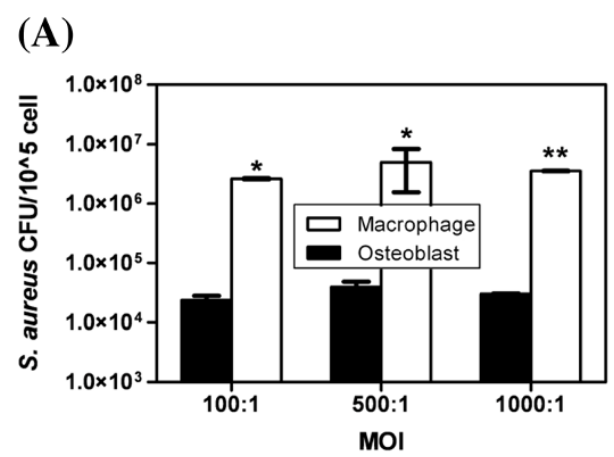

(C)

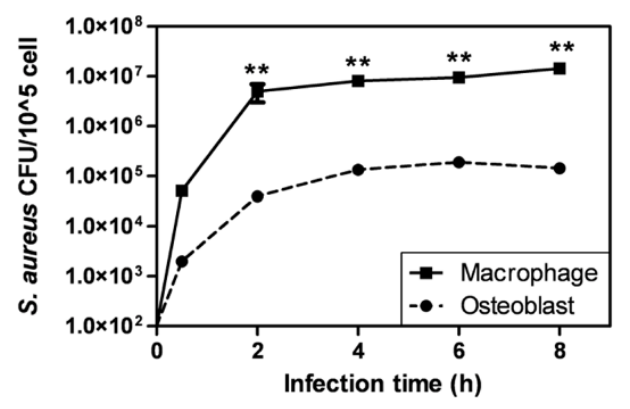

(E)

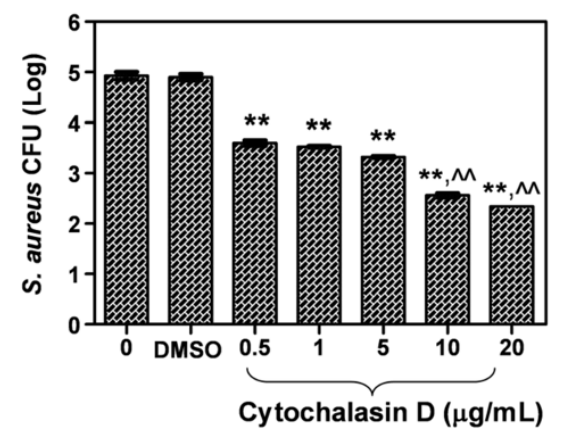

(B)

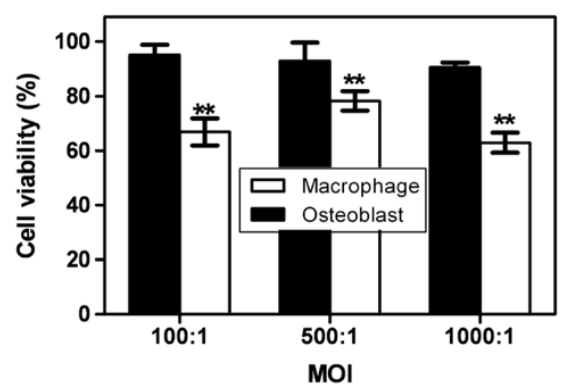

(D)

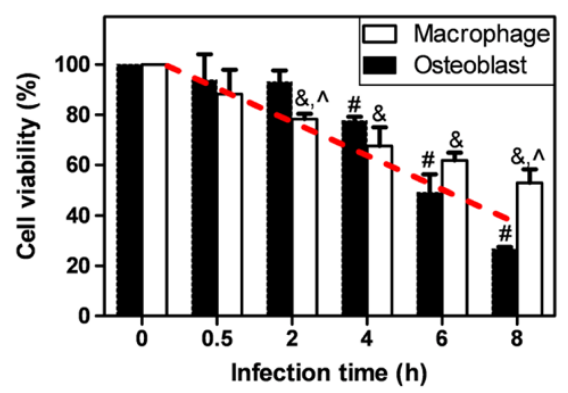

Figure 1 S. aureus infection of osteoblasts and macrophages. (A) Live intracellular S. aureus and (B) viability of osteoblasts and macrophages at different MOls (100:1, 500:1, and 1000:1) for 2 h. ${ }^{*} p<0.05$ and ${ }^{* *} p<0.001$ compared to osteoblasts at the same MOI. (C) Live intracellular S. aureus and (D) viability of osteoblasts and macrophages at an $\mathrm{MOI}$ of 500:1 for various infection times. ${ }^{* *} p<0.001$ compared to osteoblasts at the same infection time, ${ }^{\&} p<0.01$ compared to macrophages at infection times 0 and $0.5 \mathrm{~h}, \wedge p<0.01$ compared to osteoblasts at the same infection times, and ${ }^{\#} p<0.05$ compared to osteoblasts at infection times 0 and $0.5 \mathrm{~h}$. (E) Effect of cytochalasin D on S. aureus internalization in osteoblasts. ${ }^{* *} p<0.001$ compared to the controls and ${ }^{\wedge \wedge} p<0.001$ compared to $0.5,1$, and $5 \mu \mathrm{g} / \mathrm{mL}$.

on the surface of the osteoblasts after gentamicin treatment (Figure 3C); this finding was consistent with the bacterial culturing of the washing media after gentamicin treatments - no colonies were found from the washing media. The internalization of $S$. aureus within osteoblasts was found to be non-uniform as some osteoblasts had multiple $S$. aureus bacteria while others had none (Figure 3D).

\section{Biological responses of osteoblasts and macrophages upon S. aureus infection}

Significantly higher hydrogen peroxide $\left(\mathrm{H}_{2} \mathrm{O}_{2}\right)$ levels were observed at 0.5 and $1 \mathrm{~h}$ in infected osteoblasts compared to non-infected osteoblasts, i.e. control (Figure 4A). Significantly higher $\mathrm{H}_{2} \mathrm{O}_{2}$ levels were also observed following a $1 \mathrm{~h}$ infection in macrophages compared to the non-infected control (Figure 4A). No significant changes in superoxide anion $\left(\mathrm{O}_{2}^{-}\right)$production in osteoblasts were observed at the infection time periods studied (i.e. 0.5, 1, and $2 \mathrm{~h}$ ), while significantly higher $\mathrm{O}_{2}^{-}$levels were found in macrophages at 0.5 and $1 \mathrm{~h}$ infection (Figure 4B).

Significantly lower alkaline phosphatase (ALP) enzyme activity was observed at post-infection day 7 in the infected osteoblasts compared to the non-infected cells (i.e. control); no significant changes in ALP enzyme activity were found 


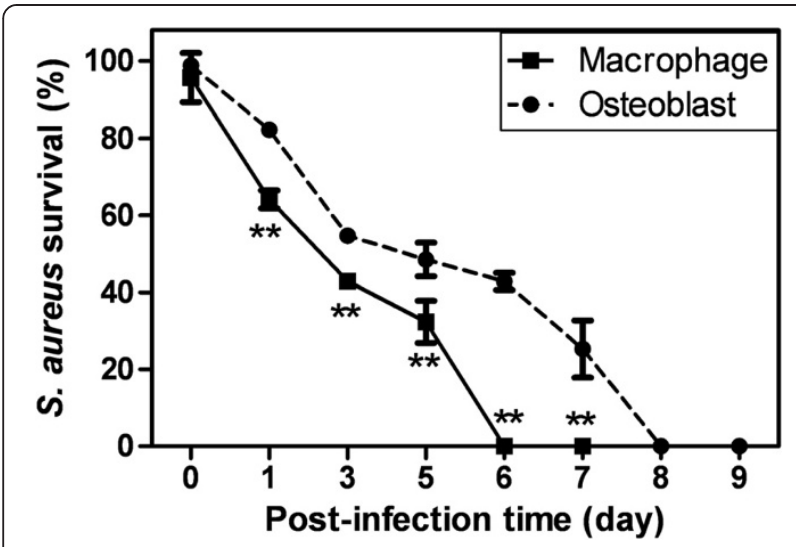

Figure 2 Survival of intracellular S. aureus within osteoblasts and macrophages after infection at an MOI of 500:1 for $2 \mathrm{~h}$.

${ }^{* *} p<0.001$ compared to osteoblasts at the same post-infection time.

between infected and non-infected osteoblasts at days 1 and 4 (Figure 4C). The macrophage phagocytosis activity studies showed that the ability to ingest bacteria was much higher for infected macrophages (83\%) compared to noninfected ones (44\%) (Figure 4D).

\section{Discussion}

S. aureus has been traditionally considered as an extracellular pathogen; however, it has been shown to invade and survive within both non-phagocytic and phagocytic cells. By nature, the internalization and survival of $S$. aureus within non-phagocytic and phagocytic cells would be expected to be different, and may play significantly different roles in related diseases. The main goal of the present study was to compare the internalization behavior and related biological responses of $S$. aureus in a non-phagocytic cell (i.e. osteoblast) and a phagocytic cell (i.e. macrophage); our findings may contribute to the understanding of the pathogenesis of many chronic and recurrent infections.

In this study, S. aureus was internalized by both osteoblasts and macrophages. The infection of osteoblasts and macrophages was observed as early as $0.5 \mathrm{~h}$ at an MOI of 500:1. With increasing infection time, the intracellular CFUs of both osteoblasts and macrophages increased significantly from $0.5 \mathrm{~h}$ to $2 \mathrm{~h}$ followed by a plateau from $2 \mathrm{~h}$ to 8 . Our data indicated that an intracellular load of approximately one $S$. aureus per osteoblast (Figure 1C) was sufficient to induce the death of approximately $10 \%$ of the osteoblast population within $2 \mathrm{~h}$ and $70 \%$ within $8 \mathrm{~h}$ (Figure 1D). Since macrophages are supposed to engulf and eliminate pathogens on contact, it was not surprising to find that, at the same infection conditions (i.e. MOI of 500:1 for 2 h), significantly more (approximately 100 fold) S. aureus (live and dead) was phagocytized by macrophages compared to those internalized by osteoblasts. Similarly, significantly more live intracellular $S$. aureus was seen in macrophages compared to osteoblasts during infection times of $2-8 \mathrm{~h}$. Macrophages had significantly lower viability at a shorter infection time period (i.e. $2 \mathrm{~h}$ ) and significantly higher survival at a longer infection time (i.e. $8 \mathrm{~h}$ ) compared to infected osteoblasts. In addition, it is possible that the accumulation of toxins produced by $S$. aureus $[29,30]$ and the significantly higher levels of $\mathrm{H}_{2} \mathrm{O}_{2}$ in infected osteoblasts and macrophages and $\mathrm{O}_{2}^{-}$in infected macrophages affected the viability of macrophages and osteoblasts; both decreased (almost linearly) with increasing infection time. Rasigade et al. reported that phenol-soluble modulins, a class of membrane-damaging exoproteins, acted as intracellular toxins and were involved in killing of the host cells like osteoblasts, and they found that the intracellular expression of $p s m \alpha$ gene resulted in extensive cell damage [31]. It seems that actin cytoskeleton formation played a major role in $S$. aureus internalization since cytochalasin D, an inhibitor that disrupts actin filament polymerization, led to up to $50 \%$ inhibition of $S$. aureus internalization. This finding was consistent with other studies $[23,32]$ where actin filament was determined to play a dominant role in $S$. aureus internalization. One limitation of this study was that MOIs lower than 100:1 were not investigated and the higher MOI may only apply to infected tissues where numerous bacteria may exist. Future studies may need to consider lower MOIs.

Note that our data confirmed that gentamicin treatment was effective in eliminating extracellular S. aureus and the post-infection CFU was indeed from live intracellular $S$. aureus. Gentamicin treatment is commonly used to eliminate extracellular bacteria [21,32], but such a procedure lacks direct confirmation of live intracellular bacteria. In this study, besides culturing the washing media collected after gentamicin treatment, the dual staining approach combined with confocal microscopy presented direct evidence that no live extracellular S. aureus was observed after the gentamicin treatment (Figure 3C).

S. aureus has been thought to be a frequent cause for several types of chronic and recurrent infections including osteomyelitis, endovascular diseases, and chronic lung infections [33], and S. aureus infections have been reported in clinical cases to persist asymptomatically with relapses occurring months or even years after apparent antimicrobial cure of the infections $[34,35]$. In these cases, S. aureus may have protected itself and escaped antibiotics and immune response of the host by "hiding" intracellularly and establishing a latent bacterial reservoir. This was supported by our observation that $S$. aureus could survive intracellularly for up to 5 and 7 days, respectively, within macrophages and osteoblasts (Figure 2). As a phagocytic cell, macrophages were obviously more effective than osteoblasts at not only phagocytizing but also destroying the 

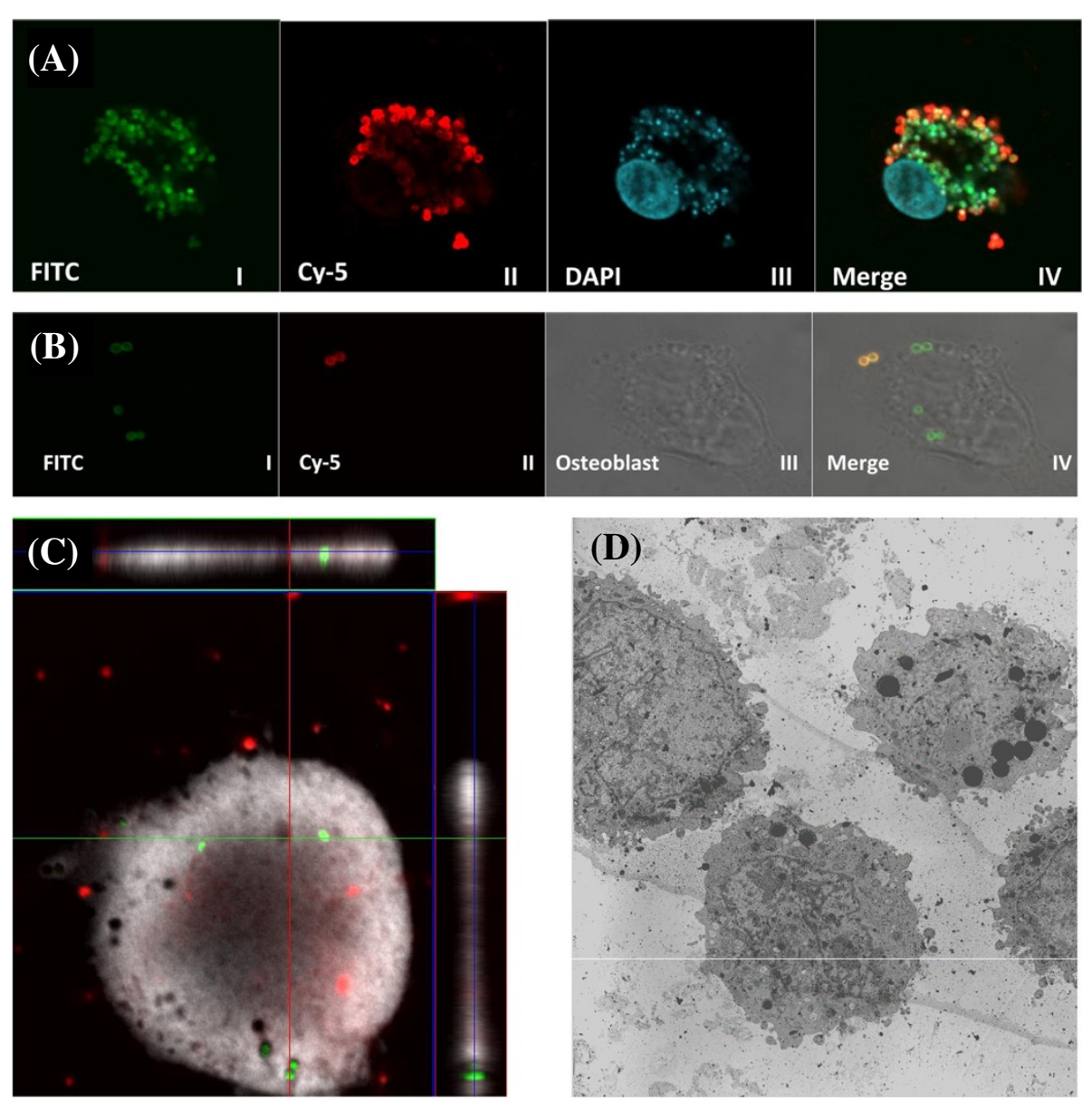

Figure 3 Visualization of intracellular S. aureus within (A) macrophages and (B-D) osteoblasts. Osteoblasts and macrophages were infected with S. aureus at an $\mathrm{MOI}$ of 500:1 for 2 h. (A and B) S. aureus was stained with FITC before infection. Infected osteoblasts and macrophages were fixed, blocked, stained first with primary antibody to S. aureus surface protein A, and then secondary antibody conjugated to Cy-5. The nuclei of the macrophages were additionally stained with DAPI. Visualized at (I) $488 \mathrm{~nm}$, (II) $633 \mathrm{~nm}$, and (III) $405 \mathrm{~nm}$. (IV) Merged images of (I), (II), and (III). As a result, intracellular S. aureus is shown in green (FITC) and extracellular S. aureus is co-localized with both red (Cy-5) and green (FITC). (C) Z-stack sections were used to confirm that all live S. aureus was inside osteoblasts as determined by the X-Y planes. Live S. aureus are green (Syto 9) and dead S. aureus are red (PI). Osteoblasts were infected with Syto 9-labeled S. aureus, then extracellular bacteria were killed with gentamicin and washed. Osteoblasts were detached from the wells and stained with PI. Approximately 20 cells (randomly selected) were examined. (D) Confirmation of intracellular S. aureus within osteoblasts using TEM.

intracellular bacteria. This was supported by our data showing that $S$. aureus infection not only significantly increased the $\mathrm{H}_{2} \mathrm{O}_{2}$ levels in macrophages at $1 \mathrm{~h}$ infection but also significantly increased the $\mathrm{O}_{2}^{-}$levels in macrophages at infection times of 0.5 and $1 \mathrm{~h}$. In contrast, $S$. aureus infection induced significantly higher levels of $\mathrm{H}_{2} \mathrm{O}_{2}$ in osteoblasts at 0.5 and $1 \mathrm{~h}$ infection but did not induce significant changes in $\mathrm{O}_{2}^{-}$levels in osteoblasts. As a result, a significantly higher number of intracellular CFUs was found in macrophages immediately after infection while significantly less intracellular $S$. aureus survived in the days following infection. Survival of $S$. aureus within host cells was also reported in tissues and other cell types. For instance, Tuchscherr et al. reported that S. aureus could persist within host cells and/or tissues for several weeks [36], survive within human lung epithelial cells for up to 2 weeks [37], persist in macrophage vacuoles for 3-4 days before escaping into the cytoplasm and causing macrophage lysis [6], and remain viable for up to 5 days within HT-29 and Caco-2 enterocytes [38]. It was proposed that, once inside osteoblasts, macrophages, or other cells, $S$. aureus may undergo phenotypic switching to small colony variants (SCVs), which are associated with increased anchoring of fibronectin-binding proteins and clumping factors on the bacterial surface [36,39]. These proteins may function as substrates for bacterial enzymes that are needed to evade phagocytic oxidative killing $[6,40]$ thereby contributing to the intracellular survival of $S$. aureus. Moreover, $S$. aureus produces catalase, which catalyzes the decomposition of $\mathrm{H}_{2} \mathrm{O}_{2}$, thereby protecting 


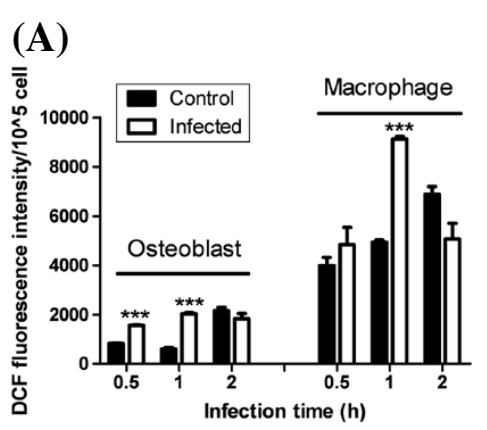

(B)
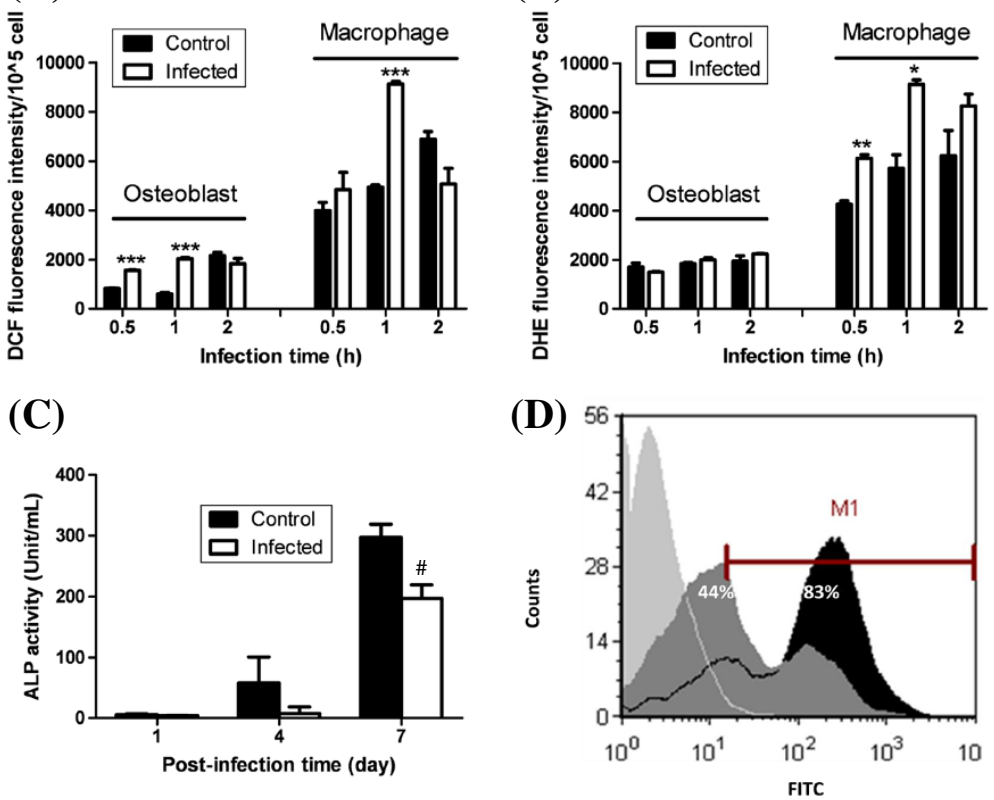

Figure 4 Cellular and molecular responses of osteoblasts and macrophages infected with S. aureus at an MOI of 500:1 for 2 h. (A) DCF fluorescence intensity as an indicator of $\mathrm{H}_{2} \mathrm{O}_{2}$ production by non-infected controls and $\mathrm{S}$. aureus-infected osteoblasts and macrophages. (B) DHE fluorescence intensity as an indicator of $\mathrm{O}_{2}^{-}$production by non-infected controls and S. aureus-infected osteoblasts and macrophages. (C) Osteoblast ALP activity measured at post-infection days 1, 4, and 7. (D) Macrophage phagocytosis activity (ingestion). Light gray area: control macrophages without incubation with S. aureus; dark gray area: non-infected macrophages; black area: infected macrophages. ${ }^{*} p<0.01,{ }^{* * *} p<0.001,{ }^{* * *} p<0.0001$, and ${ }^{\#} p<0.05$ compared to control.

itself inside host cells such as macrophages [41]. It was believed that the phenotypic switching of S. aureus may make the bacteria more resistant to antibiotics $[17,42]$. Similarly, S. epidermidis was found to persist in macrophages and also in peri-implant tissues in mice despite antibiotic treatments $[43,44]$. The survival of $S$. aureus within cells like macrophages and osteoblasts and the possible phenotypic switching of $S$. aureus may explain why antibiotics have so often failed to cure Staphylococcal infections $[2,17,36]$. In addition, the presence of antibodies (e.g. anti-tumor necrosis factor-related apoptosis-inducing ligand or TRAIL antibody) may improve the viability of infected host cells and provide better protection for the intra-cellular bacteria [45]. Alexander et al. found that in the presence of $1 \mu \mathrm{g} / \mathrm{mL}$ of anti-TRAIL antibody, the percentage of apoptotic cells decreased from the control (in the absence of antibody) of $32 \%$ to $28 \%$ [45]. Future studies may focus on investigation of the possible changes that occur to $S$. aureus after internalization into osteoblasts and macrophages and the effect of a variety of opsonins potentially present in vivo. This study was limited to in vitro cell studies which may not reflect what is happening in patients with chronic infections. In vivo studies using chronic infection animal models, which may allow monitoring of intracellular presence of $S$. aureus with time, are needed in the future.
S. aureus infection also resulted in significantly increased levels of $\mathrm{H}_{2} \mathrm{O}_{2}$ in infected osteoblasts at infection times of 0.5 and $1 \mathrm{~h}$ and in infected macrophages at infection time of $1 \mathrm{~h}$. The $\mathrm{O}_{2}^{-}$levels in infected macrophages significantly increased at infection times of 0.5 and $1 \mathrm{~h}$. The increase in reactive oxygen species indicates that $S$. aureus internalization induced significant stress in osteoblasts and macrophages which would produce such chemicals to eliminate the invading pathogens. S. aureus infection also led to much higher phagocytosis activity of macrophages and significantly lower ALP activity of osteoblasts at day 7 after infection. This effect could be associated with the significant increase in $\mathrm{H}_{2} \mathrm{O}_{2}$ and $\mathrm{O}_{2}^{-}$levels. It is noteworthy that, besides the significant changes in reactive oxygen species, $S$. aureus internalization in osteoblasts also led to significantly higher production of IL-6 and IL-12 [21,46], macrophage chemoattractant protein 1, IL-8, IP-10, RANTES [21,46], and RANK-L and prostaglandin $\mathrm{E}_{2}$ (two important molecules that can promote osteoclastogenesis and bone resorption) [47].

\section{Conclusions}

We compared S. aureus internalization in a phagocytic cell (i.e. macrophage) to a non-phagocytic cell (i.e. osteoblast) and investigated the cells' responses upon infection. We found that S. aureus could internalize within macrophages 
and osteoblasts and, upon infection, a significantly higher number of live intracellular $S$. aureus was observed in macrophages compared to osteoblasts. The viability of macrophages and osteoblasts both decreased with increasing infection time and macrophages had significantly lower viability during $2 \mathrm{~h}$ infection and significantly higher viability during $8 \mathrm{~h}$ infection compared to osteoblasts. Moreover, intracellular $S$. aureus was found to survive within macrophages and osteoblasts for approximately 5 and 7 days, respectively. The percentage of $S$. aureus survival within macrophages and osteoblasts decreased with increasing post-infection time, and the percentage of $S$. aureus survival within macrophages was significantly lower compared to that within osteoblasts. Moreover, compared to non-infected controls, S. aureus infection resulted in (i) significantly increased hydrogen peroxide production in macrophages and osteoblasts, (ii) significantly increased superoxide anion production in macrophages but not in osteoblasts, (iii) significantly lower alkaline phosphatase activity in infected osteoblasts, and (iv) higher phagocytosis activity in infected macrophages.

\section{Methods \\ Reagents}

Tryptic soy agar (TSA, w/5\% sheep blood) plates, tryptic soy broth (TSB), phosphate buffered saline (PBS), fetal bovine serum (FBS), $0.25 \%$ trypsin $/ 2.21 \mathrm{mM}$ ethylenediaminetetraacetic acid (EDTA) solution, $45 \%$ glucose solution, 7.5\% sodium bicarbonate, sodium pyruvate, and HEPES buffer were all obtained from Fisher Scientific (Pittsburgh, PA). Dulbecco's Modified Eagle Media: Nutrient Mixture F-12 (DMEM/F12) and RPMI-1640 media were purchased from LONZA (Walkersville, MD). DiI fluorescent dye, Syto-9, propidium iodide (PI), and $100 \mathrm{U} / \mathrm{mL}$ penicillin $/ 100 \mathrm{mg} / \mathrm{mL}$ streptomycin solution were from Invitrogen (Carlsbad, CA). Gentamicin, Triton X-100, cytochalasin D, dimethyl sulfoxide (DMSO), bovine serum albumin (BSA), lysostaphin, fluorescein isothiocyanate (FITC), paraformaldehyde, and glutaraldehyde were obtained from Sigma (St. Louis, MO). Primary antibody Ab20920 and goat polyclonal to rabbit IgG secondary antibody-Cy5 ab6564 were obtained from Abcam (Cambridge, MA). Dichlorofluorescin diacetate $\left(\mathrm{H}_{2} \mathrm{DCF}-\mathrm{DA}\right)$ and dihydroethidum (DHE) were from Life Technologies (Grand Island, NY).

\section{Bacteria}

S. aureus (ATCC 25923) was obtained from the American Type Culture Collection (ATCC, Manassas, VA). Bacteria were prepared as we previously reported [48-52]. Briefly, a fresh inoculum was prepared by suspending 5 colonies of $S$. aureus, grown on a blood agar plate, in $5 \mathrm{~mL}$ TSB and incubating at $37^{\circ} \mathrm{C}$ for $18 \mathrm{~h}$. After incubation, the $S$. aureus inoculum was centrifuged at $3750 \mathrm{rpm}$ for $15 \mathrm{~min}$ at $4^{\circ} \mathrm{C}$, washed once with $10 \mathrm{~mL}$ PBS, and the bacteria pellet was diluted to $(6-8) \times 10^{8} \mathrm{CFU} / \mathrm{mL}$ with sterile PBS. Next, the bacteria were centrifuged again and the bacteria pellet was then re-suspended in either DMEM/F12 for the infection of osteoblasts or in RPMI-1640 medium for the infection of macrophages; both cell culture media were free from streptomycin/penicillin and FBS.

\section{Infection of osteoblasts with S. aureus}

Rat osteoblasts (UMR-106) were obtained from ATCC and grown in full-supplemented DMEM/F12 medium containing $10 \%$ FBS and $1 \%$ penicillin/streptomycin solution. As previously reported [53,54], $3 \times 10^{5}$ cells $/ \mathrm{mL}$ were seeded in 12-well plates (Fisher Scientific) and cultured in full-supplemented DMEM/F12 medium for at least $24 \mathrm{~h}$ at $37^{\circ} \mathrm{C}$ in a $5 \% \mathrm{CO}_{2}$ incubator until they reached $\sim 80 \%$ confluence. Osteoblasts were infected and the effects of MOI and infection time on osteoblast infection were investigated: (1) To examine the effect of MOI on osteoblast infection, the osteoblast monolayer was washed 3 times with PBS and then fresh DMEM/ F12 medium was added (free from streptomycin/penicillin and FBS). Immediately, $S$. aureus was added at MOIs of 100:1, 500:1, and 1000:1 and incubated for $2 \mathrm{~h}$. (2) To examine the effect of infection time on osteoblast infection, the osteoblast monolayer was washed 3 times with PBS and then fresh DMEM/F12 medium (free from streptomycin/penicillin and FBS) was added. S. aureus was added at an MOI of 500:1 and incubated for different times, i.e. infection times, of $0.5,2,4,6$, and $8 \mathrm{~h}$. After each treatment, the osteoblast monolayer was washed 3 times with PBS and treated with $100 \mu \mathrm{g} / \mathrm{mL}$ gentamicin (an antibiotic known not to penetrate mammalian cell membranes within a few hours [55,56]) for $2 \mathrm{~h}$ at $37^{\circ} \mathrm{C}$ in a $5 \% \mathrm{CO}_{2}$ incubator. Osteoblasts were then washed 3 times with PBS and immediately lysed with $0.1 \%$ Triton $\mathrm{X}-100$ in $\mathrm{PBS}$ for $10 \mathrm{~min}$ at $37^{\circ} \mathrm{C}$; the cell lysates were diluted in PBS and plated on blood agar plates overnight. The washing PBS was collected and plated on blood agar plates overnight as well. To determine viability, osteoblasts were detached by incubating them at $37^{\circ} \mathrm{C}$ for $3 \mathrm{~min}$ in a $0.25 \%$ trypsin $/ 2.21 \mathrm{mM}$ EDTA solution; trypsinization was stopped by adding DMEM/F12 medium supplemented with 10\% FBS. Viable osteoblasts were counted using a hemocytometer (BrightLine Hausser Scientific, Horsham, PA) [57] following the trypan-blue exclusion assay which depends on cellular membrane integrity; dead cells allow the stain to penetrate while live cells do not.

\section{Infection of macrophages with S. aureus}

A rat alveolar macrophage cell-line (NR 8383) was obtained from ATCC and grown in full-supplemented RPMI-1640 medium containing 10\% FBS, 1\% streptomycin/penicillin, 
45\% glucose solution, $7.5 \%$ sodium bicarbonate, and sodium pyruvate. The infection of macrophages with $S$. aureus was studied at different MOIs and infection times. The protocols for infecting macrophages were similar to those of infecting osteoblasts as described previously. In brief, to achieve adherence, $3 \times 10^{5}$ cells $/ \mathrm{mL}$ were seeded in 12-well plates and cultured in fullsupplemented RPMI-1640 medium for at least $24 \mathrm{~h}$ at $37^{\circ} \mathrm{C}$ in a $5 \% \mathrm{CO}_{2}$ incubator. Cultured macrophages were washed 3 times with PBS and then infected with S. aureus at different MOIs (100:1, 500:1, and 1000:1) or infection times (0.5-8 h). Infected macrophages were washed, treated with gentamicin, washed again (the washing media were collected and plated on blood agar plates overnight), and then lysed to determine the number of live intracellular $S$. aureus. To determine the viability of macrophages, adherent macrophages were scraped using a cell scraper (Fisher Scientific) and combined with floating macrophages from the same sample for trypanblue exclusion assay and hemocytometry.

The viability of osteoblasts and macrophages after infection with $S$. aureus was calculated relevant to their control (non-infected) cells according to the following equation:

Viability $(\%)=\frac{\frac{\text { Number of live cell in infected sample }}{\text { Number of live and dead cells in infected sample }}}{\frac{\text { Number of live cells in control sample }}{\text { Number of live and dead cells in control sample }}}$

Note that the total cell numbers in the infected and control samples were the same at the beginning of the infection (i.e. infection time $=0 \mathrm{~h}$ ) but were different at later infection time periods (i.e. 0.5-8 h).

\section{Inhibition of S. aureus internalization in osteoblasts}

Cytochalasin D was reconstituted in 1\% DMSO. $3 \times 10^{5}$ cells $/ \mathrm{mL}$ were seeded in 12-well plates and cultured in full-supplemented DMEM/F12 medium to reach 80\% confluence. The osteoblast monolayer was washed 3 times with PBS and then fresh DMEM/F12 medium was added (free from streptomycin/penicillin and FBS) together with cytochalasin D $(0.5,1,5,10$, and $20 \mu \mathrm{g} / \mathrm{mL})$. After culturing for $30 \mathrm{~min}, \mathrm{~S}$. aureus was added at an MOI of 500:1 and further incubated for $2 \mathrm{~h}$. Following treatment with gentamicin, infected osteoblasts were lysed and plated to determine the number of live intracellular bacteria.

\section{Survival of S. aureus within osteoblasts or macrophages}

Osteoblasts or macrophages were infected with $S$. aureus at an MOI of 500:1 for $2 \mathrm{~h}$, treated with gentamicin, washed, and cultured for up to a week in DMEM/F12 (for osteoblasts) or RPMI-1640 (for macrophages) supplemented with 5\% FBS and $5 \mu \mathrm{g} / \mathrm{mL}$ lysostaphin; lysostaphin does not penetrate mammalian cell membranes for long time periods, e.g. weeks [58-60]. The cell culture medium was changed every 3 days. At post-infection days $0,1,3,5,6,7$, and/or 8 and 9, independent samples of infected cells were washed with PBS, lysed with $0.1 \%$ Triton $\mathrm{X}-100$, and plated on blood agar plates to determine the number of live intracellular $S$. aureus. The percentage of live intracellular CFUs [53] at different times following infection was calculated based on the live intracellular CFUs immediately after infection (i.e. post-infection day 0 ).

\section{Confocal microscopy}

A dual staining approach $[61,62]$ was adopted to visualize intracellular S. aureus. Osteoblasts or macrophages were cultured on rounded cover-slips for at least $24 \mathrm{~h}$ in fullsupplemented DMEM/F12 or RPMI-1640, respectively. Fresh $S$. aureus was cultured for $18 \mathrm{~h}$ at $37^{\circ} \mathrm{C}$ in a $5 \% \mathrm{CO}_{2}$ incubator. After washing the bacteria once with PBS, the pellet was stained with $100 \mu \mathrm{g} / \mathrm{mL}$ FITC in PBS for $30 \mathrm{~min}$ at room temperature prior to infection. Excess FITC was removed by washing with PBS and centrifuging at $3750 \mathrm{rpm}$ for $15 \mathrm{~min}$ at $4^{\circ} \mathrm{C}$. After infecting with the stained S. aureus for $2 \mathrm{~h}$ at an MOI of 500:1, osteoblasts were trypsinized using a $0.25 \%$ trypsin/2.21 mM EDTA solution for 30 seconds at room temperature to remove adherent extracellular S. aureus; no trypsinization was used in the macrophage samples. Osteoblasts or macrophages were then fixed with $4 \%$ paraformaldehyde in distilled water for $30 \mathrm{~min}$ at room temperature. Fixed cells were washed 3 times with PBS and blocked with $5 \%$ BSA for $1 \mathrm{~h}$ at room temperature. To further label the extracellular $S$. aureus, the fixed cells were incubated overnight at $4{ }^{\circ} \mathrm{C}$ with a primary antibody Ab20920S in 5\% BSA, washed 3 times with PBS (to remove excess free primary antibody), and then incubated in the dark with a secondary antibody-conjugated Cy5 fluorescent dye in 2.5\% BSA for $45 \mathrm{~min}$ at room temperature. After washing the excess secondary antibody with PBS, the cover-slips were flipped onto microscopic glass slides and used for image observation; macrophage samples were mounted in the presence of 4',6-diamidino-2-phenylindole (DAPI) fluorescent dye to visualize the nuclei of macrophages. Slides were visualized using a 159 Plan-Apochromat 63x/1.40 oil objective on an LSM 510 confocal microscope (Zeiss, Jena, Germany).

To confirm the presence of live intracellular S. aureus and the efficacy of gentamicin at killing extracellular $S$. aureus, osteoblasts were seeded on a rounded cover-slip overnight. The monolayer was then stained with DiI fluorescent dye for $20 \mathrm{~min}$ at $37^{\circ} \mathrm{C}$ in the dark. The monolayer was washed once with PBS and infected with Syto-9 labeled $S$. aureus as aforementioned. After gentamicin treatment, infected osteoblasts were washed 3 times with HEPES buffer and PI stain was added for $15 \mathrm{~min}$ at room temperature in the dark. Immediately after washing off 
the excess PI, the slides were examined under the LSM 510 confocal microscope and images of Z-stack sections were taken to confirm the live intracellular $S$. aureus. Z-stack sections were generated and the X-Y planes showed that all live (green) $S$. aureus was inside the osteoblasts.

\section{Transmission electron microscopy (TEM)}

Osteoblasts were infected with $S$. aureus at an MOI of 500:1 for $2 \mathrm{~h}$, washed once with PBS, and detached using trypsin-EDTA. Osteoblasts were then collected by centrifugation at $1200 \mathrm{rpm}$ at $4{ }^{\circ} \mathrm{C}$ for $7 \mathrm{~min}$, and the pellet was washed twice with PBS. Slides were then prepared as previously reported [63]. In brief, osteoblasts were fixed with $2 \%$ paraformaldehyde and $4 \%$ glutaraldehyde mixed with $0.075 \mathrm{M}$ PBS for $30 \mathrm{~min}$ at room temperature. The fixed cell mass was collected in $1.5 \mathrm{~mL}$ Eppendorf tubes. The cell pellet was washed 3 times with PBS, postfixed in $1 \%$ osmium tetroxide for $2 \mathrm{~h}$ at room temperature, washed 3 times with PBS, treated with aqueous $1 \%$ tannic acid for $1 \mathrm{~h}$ at room temperature, and then dehydrated in a gradient ethanol series. The cells were embedded in pure LR white resin solution and polymerized at $60^{\circ} \mathrm{C}$ for $24-48 \mathrm{~h}$. Thin $(0.1 \mu \mathrm{m})$ sections were cut and placed on nickel grids, stained with $2 \%$ uranyl acetate and lead citrate, and viewed using TEM (JEOL, Peabody, MA).

\section{Reactive oxygen species production}

Osteoblasts and macrophages were infected with $S$. aureus at an MOI of 500:1. At pre-determined time points $(0.5,1$, and $2 \mathrm{~h}$ ), samples of infected osteoblasts or macrophages were taken, washed once with PBS, and then incubated with $\mathrm{H}_{2}$ DCF-DA or DHE at $37^{\circ} \mathrm{C}$ for $1 \mathrm{~h}$ in the dark; separate samples were used for the staining of $\mathrm{H}_{2}$ DCF-DA and DHE. Non-infected osteoblasts and macrophages were used as controls and were treated the same as the infected cells except no $S$. aureus was added. Viable cells of infected and control samples at the pre-determined time points were obtained using hemocytometry and were used to analyze the final fluorescent data. The fluorescence intensity was measured using a fluorescent microplate reader (BioTek Instrument, Inc., Winooski, VT) at $492 \mathrm{~nm} /$ $520 \mathrm{~nm}$ for $2^{\prime}, 7^{\prime}$-dichlorofluorescein (DCF), converted intracellularly from $\mathrm{H}_{2}$ DCF-DA, and $492 \mathrm{~nm} / 620 \mathrm{~nm}$ for DHE. $\mathrm{H}_{2}$ DCF-DA and DHE are commonly used to stain intracellular $\mathrm{H}_{2} \mathrm{O}_{2}$ and $\mathrm{O}_{2}^{-}$, respectively [64]. The acetate groups of $\mathrm{H}_{2}$ DCF-DA are cleaved by intracellular esterases and oxidation and convert to highly fluorescent DCF.

\section{Osteoblast alkaline phosphatase (ALP) activity}

Osteoblasts were cultured in 12-well plates at a density of $5 \times 10^{4}$ cells $/ \mathrm{mL}$, infected at an MOI of $500: 1$ for $2 \mathrm{~h}$ following the aforementioned infection protocol. Noninfected (control) and infected osteoblasts were cultured in DMEM/F12 supplemented with 5\% FBS and $5 \mu \mathrm{g} / \mathrm{mL}$ lysostaphin solution for a week; medium was changed every 3 days. On post-infection days 1, 4, and 7, osteoblast monolayers were washed with PBS once and the ALP activity was determined using an ALP assay kit (Abcam) and expressed as Unit $/ \mathrm{mL}$.

\section{Macrophage phagocytosis assay}

Macrophage phagocytosis (ingestion) activity was tested by measuring the uptake of FITC-labeled $S$. aureus by non-infected (control) macrophages and macrophages infected with S. aureus (unlabeled) at an MOI of 500:1 for $2 \mathrm{~h}$. After incubating $5 \times 10^{5}$ cells $/ \mathrm{mL}$ non-infected (control) and infected macrophages separately with FITClabeled S. aureus at 10:1 MOI for $2 \mathrm{~h}$, macrophages (infected and non-infected) were treated with $100 \mu \mathrm{g} / \mathrm{mL}$ gentamicin for $2 \mathrm{~h}$ at $37^{\circ} \mathrm{C}$ in a $5 \% \mathrm{CO}_{2}$ incubator. Macrophages were then scraped and collected for flow cytometry analysis using BD-FACS Calibur (BD, Franklin Lakes, NJ); 10,000 events were collected. Data were acquired in logarithmic mode for the forward scatter (FSC), side scatter (SSC), and green fluorescence channel FL-1H (i.e. FITC). Control macrophages were subjected to the same experimental protocols as the infected cells but without infection with $S$. aureus. The percentage of macrophages with FITC fluorescent intensity corresponds to the ingestion activity of macrophages.

\section{Statistical analysis}

Statistical analyses were performed using JMP Statistical Visualization Software (SAS Institute, Cary, NC). Experiments were repeated at least twice on separate days to verify reproducibility. All data were expressed as mean \pm SD and analyzed using one-way analysis of variance (ANOVA). Statistical significance was set at $p<0.05,0.01,0.001$, or 0.0001 .

\section{Ethics statement}

No human subjects, human material, or human data were involved.

\section{Competing interests}

The authors declare that they have no competing interests.

\section{Authors' contributions}

$\mathrm{TH}$ participated in the design of the study, carried out the experiments, assisted in the data interpretation, and drafted the manuscript. BL conceived and designed the study, interpreted data, and revised the manuscript. Both authors read and approved the final manuscript.

\section{Authors' information}

$\mathrm{TH}$ is currently a postdoctoral research associate at the Department of Microbiology and Immunology at the University of Maryland in Baltimore. BL is an Associate Professor in the Department of Orthopaedics, West Virginia University and a member of American Society for Microbiology (ASM), Orthopaedic Research Society (ORS), Society for Biomaterials (SFB), and American Chemical Society (ACS). 


\section{Acknowledgements}

We acknowledge financial support from the AO Foundation (Project S-13-15 L was supported by the AO Foundation). We acknowledge transmission electron microscopy support services provided by the WVU Tissue Processing and Analysis Core Facility. This facility is supported, in part, by a Center of Biomedical Research Excellence Award (NCRR P20 RR-15574) to the Sensory Neuroscience Research Center. Microscope experiments and image analysis were also performed in part in the West Virginia University Imaging Facility, which is supported in part by the Mary Babb Randolph Cancer Center and NIH grant P20 RR016440. Flow cytometry experiments were carried out at the WVU Flow Cytometry Core Facility, which is supported in part by grants P30GM103488 and P30RR032138. We acknowledge Dr. Gerald R. Hobbs for statistical analysis, Dr. Kathy Brundage for assistance with flow cytometry analysis, and Suzanne Danley for copyediting and proofreading.

\section{Author details}

'Department of Orthopaedics, School of Medicine, West Virginia University, Morgantown, WV 26506, USA. ${ }^{2}$ Department of Basic Pharmaceutical Sciences, School of Pharmacy, West Virginia University, Morgantown, WV 26506, USA.

${ }^{3}$ Mary Babb Randolph Cancer Center, Morgantown, WV 26506, USA.

Received: 7 April 2014 Accepted: 18 July 2014

Published: 25 July 2014

\section{References}

1. Darouiche RO: Treatment of infections associated with surgical implants. N Engl J Med 2004, 350(14):1422-1429.

2. von Eiff C, Becker K, Metze D, Lubritz G, Hockmann J, Schwarz T, Peters G: Intracellular persistence of Staphylococcus aureus small-colony variants within keratinocytes: A cause for antibiotic treatment failure in a patient with Darier's disease. Clin Infect Dis 2001, 32(11):1643-1647.

3. Lentino JR: Prosthetic joint infections: Bane of orthopedists, challenge for infectious disease specialists. Clin Infect Dis 2003, 36(9):1157-1161.

4. Berendt T, Byren I: Bone and joint infection. Clin Med 2004, 4(6):510-518.

5. Lew DP, Waldvogel FA: Osteomyelitis. Lancet 2004, 364(9431):369-379.

6. Kubica M, Guzik K, Koziel J, Zarebski M, Richter W, Gajkowska B, Golda A, Maciag-Gudowska A, Brix K, Shaw L, Foster T, Potempa J: A potential new pathway for Staphylococcus aureus dissemination: the silent survival of S. aureus phagocytosed by human monocyte-derived macrophages. PLoS One 2008, 3(1):e1409.

7. Gresham HD, Lowrance JH, Caver TE, Wilson BS, Cheung AL, Lindberg FP: Survival of Staphylococcus aureus inside neutrophils contributes to infection. J Immunol 2000, 164(7):3713-3722.

8. Voyich JA, Braughton KR, Sturdevant DE, Whitney AR, Said-Salim B, Porcella SF, Long RD, Dorward DW, Gardner DJ, Kreiswirth BN, Musser JM, DeLeo FR: Insights into mechanisms used by Staphylococcus aureus to avoid destruction by human neutrophils. J Immuno/ 2005, 175(6):3907-3919.

9. Baughn R, Bonventre PF: Phagocytosis and intracellular killing of Staphylococcus aureus by normal mouse peritoneal macrophages. Infect Immun 1975, 12(2):346-352.

10. Hudson MC, Ramp WK, Nicholson NC, Williams AS, Nousiainen MT: Internalization of Staphylococcus aureus by cultured osteoblasts. Microb Pathog 1995, 19(6):409-419.

11. Krut $\mathrm{O}$, Sommer $\mathrm{H}$, Kronke M: Antibiotic-induced persistence of cytotoxic Staphylococcus aureus in non-phagocytic cells. J Antimicrob Chemother 2004, 53(2):167-173.

12. Almeida RA, Matthews KR, Cifrian E, Guidry AJ, Oliver SP: Staphylococcus aureus invasion of bovine mammary epithelial cells. J Dairy Sci 1996, 79(6):1021-1026

13. Vesga O, Groeschel MC, Otten MF, Brar DW, Vann JM, Proctor RA: Staphylococcus aureus small colony variants are induced by the endothelial cell intracellular milieu. J Infect Dis 1996, 173(3):739-742.

14. Balwit JM, Vanlangevelde P, Vann JM, Proctor RA: Gentamicin-resistant menadione and hemin auxotrophic staphylococcus-aureus persist within cultured endothelial-cells. J Infect Dis 1994, 170(4):1033-1037.

15. Garzoni C, Kelley WL: Staphylococcus aureus: new evidence for intracellular persistence. Trends Microbiol 2009, 17(2):59-65.

16. Vriesema AJM, Beekhuizen H, Hamdi M, Soufan A, Lammers A, Willekens B, Bakker O, Welten AGA, Veltrop MHAM, van de Gevel JS, Dankert J, Zaat SA: Altered gene expression in Staphylococcus aureus upon interaction with human endothelial cells. Infect Immun 2000, 68(4):1765-1772.
17. Ellington $J K$, Harris M, Hudson MC, Vishin S, Webb LX, Sherertz R: Intracellular Staphylococcus aureus and antibiotic resistance: Implications for treatment of staphylococcal osteomyelitis. J Orthop Res 2006, 24(1):87-93.

18. Armstead AL, Li BY: Nanomedicine as an emerging approach against intracellular pathogens. Int J Nanomedicine 2011, 6:3281-3293.

19. Favus MJ, American Society for Bone and Mineral Research: Primer on the Metabolic Bone Diseases and Disorders of Mineral Metabolism. 6th edition. Washington, DC: American Society for Bone and Mineral Research; 2006.

20. Bost KL, Ramp WK, Nicholson NC, Bento JL, Marriott I, Hudson MC: Staphylococcus aureus infection of mouse or human osteoblasts induces high levels of interleukin-6 and interleukin-12 production. J Infect Dis 1999, 180(6):1912-1920.

21. Wright KM, Friedland JS: Differential regulation of chemokine secretion in tuberculous and staphylococcal osteomyelitis. J Bone Miner Res 2002, 17(9):1680-1690.

22. Tucker KA, Reilly SS, Leslie CS, Hudson MC: Intracellular Staphylococcus aureus induces apoptosis in mouse osteoblasts. FEMS Microbiol Lett 2000, 186(2):151-156.

23. Ellington JK, Reilly SS, Ramp WK, Smeltzer MS, Kellam JF, Hudson MC: Mechanisms of Staphylococcus aureus invasion of cultured osteoblasts. Microb Pathog 1999, 26(6):317-323.

24. Allardyce RA, Wang Y, Rogers GR, Gillespia WJ, Doyle JS: The destruction of bone by neutrophils. Chin Med J 1995, 108(9):708-709.

25. Amer AO, Swanson MS: A phagosome of one's own: a microbial guide to life in the macrophage. Curr Opin Microbiol 2002, 5(1):56-61.

26. Staali L, Bauer S, Morgelin M, Bjorck L, Tapper H: Streptococcus pyogenes bacteria modulate membrane traffic in human neutrophils and selectively inhibit azurophilic granule fusion with phagosomes. Cell Microbiol 2006, 8(4):690-703.

27. Haslett C, Savill JS, Whyte MKB, Stern M, Dransfield I, Meagher LC: Granulocyte apoptosis and the control of inflammation. Philos T Roy Soc B 1994, 345(1313):327-333.

28. Petti CA, Fowler VG: Staphylococcus aureus bacteremia and endocarditis. Infect Dis Clin N Am 2002, 16(2):413.

29. Haslinger-Loffler B, Kahl BC, Grundmeier M, Strangfeld K, Wagner B, Fischer U, Cheung AL, Peters G, Schulze-Osthoff K, Sinha B: Multiple virulence factors are required for Staphylococcus aureus-induced apoptosis in endothelial cells. Cell Microbiol 2005, 7(8):1087-1097.

30. Haslinger B, Strangfeld K, Peters G, Schulze-Osthoff K, Sinha B: Staphylococcus aureus alpha-toxin induces apoptosis in peripheral blood mononuclear cells: role of endogenous tumour necrosis factor-alpha and the mitochondrial death pathway. Cell Microbiol 2003, 5(10):729-741.

31. Rasigade JP, Trouillet-Assant S, Ferry T, Diep BA, Sapin A, Lhoste Y, Ranfaing J, Badiou C, Benito Y, Bes M, Couzon F, Tigaud S, Lina G, Etienne J, Vandenesch F, Laurent F: PSMs of hypervirulent Staphylococcus aureus act as intracellular toxins that kill infected osteoblasts. PLoS One 2013, 8(5):e63176.

32. Jevon M, Guo CB, Ma BC, Mordan N, Nair SP, Harris M, Henderson B, Bentley G, Meghij S: Mechanisms of internalization of Staphylococcus aureus by cultured human osteoblasts. Infect Immun 1999, 67(5):2677-2681.

33. Lowy FD: Staphylococcus aureus infections. N Engl J Med 1998, 339(8):520-532.

34. von Eiff C, Bettin D, Proctor RA, Rolauffs B, Lindner N, Winkelmann W, Peters G: Recovery of small colony variants of Staphylococcus aureus following gentamicin bead placement for osteomyelitis. Clin Infect Dis 1997, 25(5):1250-1251

35. Proctor RA, van Langevelde P, Kristjansson M, Maslow JN, Arbeit RD: Persistent and relapsing infections associated with small-colony variants of Staphylococcus aureus. Clin Infect Dis 1995, 20(1):95-102.

36. Tuchscherr L, Medina E, Hussain M, Volker W, Heitmann V, Niemann S, Holzinger D, Roth J, Proctor RA, Becker K, Peters G, Löffler B: Staphylococcus aureus phenotype switching: an effective bacterial strategy to escape host immune response and establish a chronic infection. EMBO Mol Med 2011, 3(3):129-141.

37. Garzoni C, Francois P, Huyghe A, Couzinet S, Tapparel C, Charbonnier Y, Renzoni A, Lucchini S, Lew DP, Vaudaux P, Kelley WL, Schrenzel J: A global view of Staphylococcus aureus whole genome expression upon internalization in human epithelial cells. BMC Genomics 2007, 8:171.

38. Hess BJ, Henry-Stanley MJ, Erickson EA, Wells CJ: Intracellular survival of Staphylococcus aureus within cultured enterocytes. I Surg Res 2003, 114(1):42-49. 
39. Thwaites GE, Gant V: Are bloodstream leukocytes Trojan Horses for the metastasis of Staphylococcus aureus? Nat Rev Microbiol 2011, 9(3):215-222.

40. Melvin JA, Murphy CF, Dubois LG, Thompson JW, Moseley MA, McCafferty DG: Staphylococcus aureus sortase a contributes to the trojan horse mechanism of immune defense evasion with its intrinsic resistance to Cys184 oxidation. Biochem Us 2011, 50(35):7591-7599.

41. Das D, Bishayi B: Staphylococcal catalase protects intracellularly survived bacteria by destroying $\mathrm{H} 2 \mathrm{O} 2$ produced by the murine peritoneal macrophages. Microb Pathog 2009, 47(2):57-67.

42. McNamara PJ, Proctor RA: Staphylococcus aureus small colony variants, electron transport and persistent infections. Int J Antimicrob Ag 2000 14(2):117-122.

43. Boelens JJ, Dankert J, Murk JL, Weening JJ, van der Poll T, Dingemans KP Koole L, Laman JD, Zaat SA: Biomaterial-associated persistence of Staphylococcus epidermidis in pericatheter macrophages. $J$ Infect Dis 2000, 181(4):1337-1349.

44. Broekhuizen CAN, de Boer L, Schipper K, Jones CD, Quadir S, Vandenbroucke-Grauls CMJE, Zaat SAJ: Staphylococcus epidermidis is cleared from biomaterial implants but persists in peri-implant tissue in mice despite rifampicin/vancomycin treatment. J Biomed Mater Res A 2008, 85A(2):498-505.

45. Alexander EH, Rivera FA IM, Anguita J, Bost KL, Hudson MC: Staphylococcus aureus-induced tumor necrosis factor-related apoptosis-inducing ligand expression mediates apoptosis and caspase- 8 activation in infected osteoblasts. BMC Microbiol 2003, 3:5

46. Marriott I, Gray DL, Rati DM, Fowler VG, Stryjewski ME, Levin LS, Hudson MC, Bost KL: Osteoblasts produce monocyte chemoattractant protein-1 in a murine model of Staphylococcus aureus osteomyelitis and infected human bone tissue. Bone 2005, 37(4):504-512.

47. Somayaji SN, Ritchie S, Sahraei M, Marriott I, Hudson MC: Staphylococcus aureus induces expression of receptor activator of NF-kappaB ligand and prostaglandin E2 in infected murine osteoblasts. Infect Immun 2008, 76(11):5120-5126

48. Boyce BM, Lindsey BA, Clovis NB, Smith ES, Hobbs GR, Hubbard DF, Emery SE, Barnett JB, Li B: Additive effects of exogenous IL-12 supplementation and antibiotic treatment in infection prophylaxis. J Orthop Res 2012, 30(2):196-202.

49. Li HS, Ogle H, Jiang BB, Hagar M, Li BY: Cefazolin embedded biodegradable polypeptide nanofilms promising for infection prevention: a preliminary study on cell responses. J Orthop Res 2010, 28(8):992-999.

50. Li B, Jiang B, Dietz MJ, Smith ES, Clovis NB, Rao KM: Evaluation of local MCP-1 and IL-12 nanocoatings for infection prevention in open fractures. J Orthop Res 2010, 28(1):48-54.

51. Li B, Jiang B, Boyce BM, Lindsey BA: Multilayer polypeptide nanoscale coatings incorporating IL-12 for the prevention of biomedical device-associated infections. Biomaterials 2009, 30(13):2552-2558

52. Jiang BB, Li BY: Polypeptide nanocoatings for preventing dental and orthopaedic device-associated infection: $\mathrm{pH}$-induced antibiotic capture, release, and antibiotic efficacy. J Biomed Mater Res B 2009, 88B(2):332-338.

53. Noore J, Noore A, Li BY: Cationic Antimicrobial Peptide LL-37 Is Effective against both Extra- and Intracellular Staphylococcus aureus. Antimicrob Agents Chemother 2013, 57(3):1283-1290.

54. Hamza T, Dietz M, Pham D, Clovis N, Danley S, Li B: Intra-cellular Staphylococcus aureus alone causes infection in vivo. Eur Cell Mater 2013, 25:341-350. discussion 350

55. Eze MO, Yuan L, Crawford RM, Paranavitana CM, Hadfield TL, Bhattacharjee AK, Warren RL, Hoover DL: Effects of opsonization and gamma interferon on growth of Brucella melitensis $16 \mathrm{M}$ in mouse peritoneal macrophages in vitro. Infect Immun 2000, 68(1):257-263.

56. Murillo O, Pachon ME, Euba G, Verdaguer R, Carreras M, Cabellos C, Cabo J, Guidiol F, Ariza J: Intracellular antimicrobial activity appearing as a relevant factor in antibiotic efficacy against an experimental foreign-body infection caused by Staphylococcus aureus. J Antimicrob Chemoth 2009, 64(5):1062-1066

57. Likibi F, Jiang BB, Li BY: Biomimetic nanocoating promotes osteoblast cell adhesion on biomedical implants. J Mater Res 2008, 23(12):3222-3228.

58. Easmon C, Lanyon H, Cole P: Use of lysostaphin to remove cell-adherent staphylococci during in vitro assays of phagocyte function. $\mathrm{Br} J$ Exp Pathol 1978, 59(4):381.
59. Maurin M, Raoult D: Use of aminoglycosides in treatment of infections due to intracellular bacteria. Antimicrob Agents Chemother 2001, 45(11):2977-2986.

60. Kumar JK: Lysostaphin: an antistaphylococcal agent. Appl Microbiol Biotechnol 2008, 80(4):555-561.

61. Heesemann J, Laufs R: Double immunofluorescence microscopic technique for accurate differentiation of extracellularly and intracellularly located bacteria in cell-culture. J Clin Microbio/ 1985, 22(2):168-175.

62. Agerer F, Waeckerle $S$, Hauck CR: Microscopic quantification of bacterial invasion by a novel antibody-independent staining method. J Microbiol Meth 2004, 59(1):23-32.

63. Li H, Hamza T, Tidwell JE, Clovis N, Li B: Unique antimicrobial effects of platelet-rich plasma and its efficacy as a prophylaxis to prevent implantassociated spinal infection. Adv Healthcare Mater 2013, 2(9):1277-1284.

64. Bass DA, Parce JW, Dechatelet LR, Szejda P, Seeds MC, Thomas M: Flow cytometric studies of oxidative product formation by neutrophils - a graded response to membrane stimulation. J Immunol 1983, 130(4):1910-1917.

doi:10.1186/s12866-014-0207-5

Cite this article as: Hamza and Li: Differential responses of osteoblasts and macrophages upon Staphylococcus aureus infection. BMC Microbiology 2014 14:207.

\section{Submit your next manuscript to BioMed Central and take full advantage of:}

- Convenient online submission

- Thorough peer review

- No space constraints or color figure charges

- Immediate publication on acceptance

- Inclusion in PubMed, CAS, Scopus and Google Scholar

- Research which is freely available for redistribution 